\title{
Examination of hepato-renal functions and lipid panel among pregnant women with preeclampsia in Sétif, Algeria
}

\author{
Romyla Bourouba, ${ }^{1}$ Kaouthar Benantar, ${ }^{1}$ Chaima Ayati, ${ }^{1}$ Lina Hedna, ${ }^{1}$ Kenza Gherbi, ${ }^{1}$ Farida Djabi ${ }^{2,3}$ \\ ${ }^{1}$ Department of Biology and Animal Physiology, Faculty of Nature and Life Sciences; ${ }^{2}$ Department of Medicine, \\ Faculty of Medical Sciences; ${ }^{3}$ Laboratory of Biotechnology and Genomic in Medical Sciences, Ferhat Abbas Sétif 1 \\ University, Sétif, Algeria
}

\begin{abstract}
Preeclampsia (PE) is a multisystem pregnancy disease inflecting maternal and fetal mortality and morbidity. This case-control study aims to determine the biochemical changes in lipid profile, hepatic and renal functions among sixty late-onset preeclamptic women compared to sixty age-matching normotensive pregnant women from the Maternity Hospital in Sétif, Algeria. Several biomarkers were collected and have been determined by appropriate kits. Association between various parameters was evaluated using Pearson's correlation coefficient, with significance at $\mathrm{p}<0.05$. The $\mathrm{PE}$ women showed a significant increase in serum aminotransferase, gamma-glutamyl-transferase, alkaline phosphatase, as well as total cholesterol, triglycerides, urea, uric acid, and creatinine levels. However, a significant decrease in platelets, total protein, albumin, and plasma sodium levels was found in PE group. A positive correlation between aminotransferases and renal biomarkers was observed. PE has deleterious effects on liver and renal func-
\end{abstract}

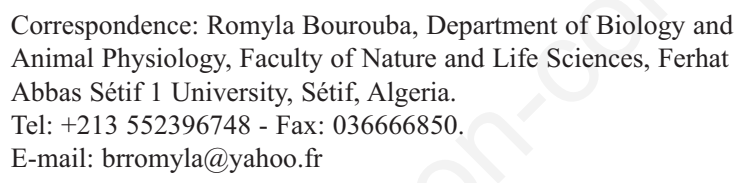

Key words: Preeclampsia; liver enzymes; renal function; lipid profile; Algeria.

Acknowledgments: The authors wish to thank the women who agreed to participate to the presented study. We are grateful to the Sétif University Maternity Hospital for providing samples and cooperation in this study.

Conflict of interest: The authors declare no conflict of interest.

Received for publication: 15 April 2020.

Accepted for publication: 8 August 2020.

${ }^{\circ}$ Copyright: the Author(s), 2020

Licensee PAGEPress, Italy

Journal of Biological Research 2020; 93:9035

doi:10.4081/jbr.2020.9035

This article is distributed under the terms of the Creative Commons Attribution Noncommercial License (by-nc 4.0) which permits any noncommercial use, distribution, and reproduction in any medium, provided the original author(s) and source are credited. tions, and complication's progression could be predicted by evaluating hepatic and renal biomarkers as well as lipid profile. Further studies on maternal and neonatal outcomes in cases of PE are needed for a better understanding of this disease's pathophysiology in Algeria.

\section{Introduction}

In developing countries where access to health care is limited, Preeclampsia (PE) is a leading cause of maternal mortality, with estimates of $>60,000$ maternal deaths per year. ${ }^{1} \mathrm{PE}$ is a pregnancy-specific public health disorder characterized by blood pressures of 140/90 mm $\mathrm{Hg}$ or higher combined with urinary protein excretion of $\geq 300 \mathrm{mg} /$ day, after 20 weeks of gestation in a previously normotensive woman. ${ }^{2}$ Despite the discovery of many promising insights every year, the exact pathogenesis of PE continue to be poorly defined. ${ }^{3}$ The factors that have been postulated to influence the risk of $\mathrm{PE}$ in various studies include multiple pregnancy, diabetes, gestational diabetes and obesity, ${ }^{4}$ older maternal age, history of abortion and maternal diet. ${ }^{5} \mathrm{PE}$ is associated with intrauterine fetal growth retardation, preterm birth, stillbirth, perinatal death, further to maternal outcomes, including antepartum and postpartum hemorrhage, cerebrovascular accident, ${ }^{3}$ placental abruption, eclamptic seizures, heart failure, and maternal death. ${ }^{6}$

Abnormal liver function occurs in $20-30 \%$ of pregnancies complicated by $\mathrm{PE}$ and eclampsia. In $\mathrm{PE}$ accompanied by Hemolysis Elevated Liver Enzymes Low Platelet count (HELLP) syndrome, there is an elevation in transaminases liver enzyme levels and hyperbilirubinemia, especially in the presence of hemolysis. ${ }^{7}$ Routine investigation of women with preeclampsia includes determination of liver function test including, Aspartate AminoTransferase (AST), Alanine Amino-Transferase (ALT), Lactate Dehydrogenase (LDH), bilirubin, and albumin levels, but there are controversies for association between these parameters and severity of PE in literature. ${ }^{8}$ Additionally, although intrinsic renal injury specific to pregnancy is seen in $40 \%$ of severe PE cases, eclampsia and the HELLP syndrome, ${ }^{9}$ very few studies have given an optimum cut-off for renal markers in predicting hypertensive disorders of pregnancy, especially in developing settings. ${ }^{10}$ Compared to normal pregnancies, in case of $\mathrm{PE}$ there will be more endocrinological alterations in lipid metabolism. ${ }^{11}$

As the women's health is important during pregnancy, especially who are at high risk, without clear records estimating and exploring the pathogenesis of preeclampsia in Algeria, to the authors' knowledge, this is the first report to assess biochemical 
liver, kidney markers, and lipid profile in pregnant women and their association with late onset PE in patients at Sétif region in Algeria.

\section{Materials and Methods}

\section{Study population}

A case-control study was designed to include 60 women with normal pregnancies (controls) and 60 patients with late-onset preeclampsia. All cases and controls were primiparous mothers with singleton babies at the end of the third trimester of pregnancy.

Patients were enrolled between November 2016 and April 2017 as a part of the study conducted in Obstetrics and High-Risk Pregnancy (HRP) Unit of the Maternity Hospital in Sétif, Algeria. Informed written consent was obtained. The criteria of the International Society for the Study of Hypertension in Pregnancy were used to define late-onset Preeclampsia, as new-onset hypertension that developed after 34 weeks of gestation: systolic or diastolic blood pressure $\geq 140$ and/or $\geq 90 \mathrm{~mm} \mathrm{Hg}$, respectively, measured on two consecutive measurements (at least 4 hours apart) and proteinuria (two random urine patients specimens obtained 4 hours containing $\geq 1+$ by dipstick screening, and then, if positive quantifying with a urine ratio $\geq 30 \mathrm{mg} / \mathrm{mmol}$ in a 24 -hour urine collection), in addition to creatinine $\geq 1.02 \mathrm{mg} / \mathrm{dL}$, or hematological disturbances. ${ }^{12}$

Patients with PE presented some symptoms (face edema, headache, abdominal pain, and weakness). They were administrated with methyldopa ( $250 \mathrm{mg}) 4 /$ day. Exclusion criteria were: twin pregnancies, preexisting maternal chronic medical problems, chronic hypertension, maternal heart disease, diabetes mellitus, history of renal diseases, chronic liver diseases, prior preeclampsia, previous family history of PE, pre-gestational diabetes.

Controls were pregnant women who were attending the Maternity for a routine prenatal visit in pregnancy with completely normal test results. The healthy normotensive pregnancies were diagnosed based on clinical, biochemical findings and none of them had preexisting hypertensive disorders, diabetes mellitus, or clinically detected hepatic, renal, or hematological diseases. Also, controls were assigned to cases by assuring that both were from the same recruitment center, had the same gestational age.

\section{Sample collections}

The baseline data comprising age, gestational age, blood pressure, maternal height and weight, parity, education level, antecedent disease, diet were obtained. Fasting blood samples (ten milliliter) were collected at the time of the prenatal visit and/or of the admission at the HRP Unit and at least two -week's interval from the first admission day until delivery. Each patient had at least three samples collected during the following gestational age intervals: 34 and 38 weeks. The blood samples were collected into EDTA tube for the Complete Blood Count (CBC), and into heparinized tubes for the assay of total protein, albumin, AST, ALT, ALP, GGT, sodium, potassium, Total Cholesterol (TC), Triglycerides (TG), urea, creatinine, and uric acid. Also, spot $24 \mathrm{~h}$ urine samples were collected in the morning from all participants.

\section{Measurements}

To measure $\mathrm{CBC}$ parameters, an automated blood counter Swelab Alfa Plus Basic (Spånga, Sweden) was used after calibration. ALT, AST, ${ }^{13} \mathrm{ALP},{ }^{14}$ and $\mathrm{GGT}^{15}$ were assessed based on spec- trophotometric methods by a Cobas c111 autoanalyzer (Mannheim, Germany). Electrolytes were analyzed with ion selective electrode on Hitachi 902 auto-analyzer (Japan). ${ }^{16}$ Lipid profile was estimated by automatic analyzers using conventional methods on Hitachi 902 auto-analyzer (Japan). ${ }^{17}$ Plasma uric acid was measured by modified uricase method, ${ }^{18}$ creatinine was estimated by modified kinetic Jaffe's method immediately on Hitachi 902 autoanalyzer (Japan). Testing for proteinuria was performed with multistix urine reagent strips (Siemens) from PE patients. Two readings of $1+(30 \mathrm{mg} \%)$ were considered as PE. The quantitative determination of protein in urine was based on the method described by Luxton et al., ${ }^{19}$ on Roche cobas c 311 autoanalyzer (Germany).

\section{Statistical analysis}

The data were analyzed using IBM SPSS version 19.0, using independent t-test to compare the groups. Association between various parameters was evaluated using Pearson's correlation coefficient, with significance at $\mathrm{p}<0.05$.

\section{Results}

The highest frequency (30\%) of women with PE observed in the age range 28-32 years. The Body Mass Index (BMI) mean of $\mathrm{PE}$ women was $32.44 \pm 0.76 \mathrm{Kg} / \mathrm{m}^{2}$ compared to controls $(30.27$ $\mathrm{Kg} / \mathrm{m}^{2} \pm 0.99$ ) (Table 1). Regarding blood pressure, there was a significant increase in both the systolic and diastolic blood pressure among preeclamptic patients, in addition to a strong proteinuria in PE patients (Table 1).

In Table 2, the current results show a non-significant difference of hematological parameters: Red Blood Cells (RBC), White Blood Cells (WBC), Haemoglobin ( $\mathrm{Hb}$ ), and Haematocrit (Ht) between normo-pregnant women and patients. However, the Platelet (PLT) levels were significantly lower among PE pregnant women (147.54 \pm 6.64 vs $\left.240.2 \pm 11.4410^{3} / \mathrm{mm}^{3}\right)$.

The liver function's biomarkers of control and preeclamptic group are given in Table 3. There was a significant increase of transaminases in PE patients compared to controls. The mean values of AST in PE group were 26.18 $\pm 3.89 \mathrm{U} / \mathrm{L}$ compared to $17.33 \pm 0.89$ $\mathrm{U} / \mathrm{L}$ in controls $(\mathrm{p}<0.05)$. The mean values of serum ALT in cases were $19.51 \pm 3.39 \mathrm{U} / \mathrm{L}$ and in the controls, it was $10.70 \pm 0.62 \mathrm{U} / \mathrm{L}$ $(\mathrm{p}<0.05)$. Moreover, the GGT and ALP mean levels shows a highly significant difference between the two groups (Table 3).

Furthermore, current results showed that the mean plasma of urea, creatinine, and uric acid levels raised significantly $(p<0.05)$ among preeclamptic group when compared with normotensive controls. TC and TG levels were also significantly higher among PE group compared to control women (Table 4). However, as shown in Table 4, the plasma total protein and albumin means were significantly $(\mathrm{p}<0.05)$ lower among preeclamptic group compared to normotensive control group.

Results show also a significant decrease $(p<0.05)$ in the mean plasma sodium value among preeclamptic group when compared to normotensive controls, whereas, there was a significant increase in the mean plasma potassium levels increased significantly among PE patients (Table 4). There was a significant and positive association between the ALT and uric acid and creatinine $(\mathrm{p}<0.05)$; as well as AST and urea among preeclamptic women. Potassium was observed to correlate positively with urea, uric acid, and creatinine. There was a positive association between urea and creatinine, uric acid and albumin (Table 5). 
Table 1. The clinical characteristics of controls and participants (mean $\pm \mathrm{SD}$ ).

\begin{tabular}{lccc}
\hline Variable & Preeclamptic group $(n=60)$ & Control group $(n=60)$ & 0.55 \\
Maternal age (years) & $30.5 \pm 1.18$ & $29.73 \pm 1.20$ & 0.06 \\
Gestational age (weeks) & $36 \pm 2.61$ & $37 \pm 1.19$ & $0.00003^{*}$ \\
\hline Systolic BP (mm Hg) & $144.5 \pm 2.67$ & $108 \pm 1.34$ & 0.00085 \\
Diastolic BP (mm Hg) & $110.44 \pm 8.16$ & $74.12 \pm 6.28$ & 0.20 \\
\hline BMI (Kg/m2) & $32.30 \pm 0.76$ & $30.64 \pm 0.88$ & Absent \\
Proteinuria (mg/mmol) & 370 & . & \\
\hline
\end{tabular}

BP, Blood pressure; BMI, body mass index (calculated as weight in kilograms divided by the square of height in meters); *Statistically significant $(<0.05)$.

Table 2. Complete blood count among preeclamptic patient and controls.

\begin{tabular}{lccc} 
Analytes & Preeclamptic groupmean \pm SD $(n=60)$ & Control groupmean $\pm S D(n=60)$ & P value \\
RBC $\left(10^{6} / \mathrm{mm}^{3}\right)$ & $4.13 \pm 0.15$ & $3.99 \pm 0.05$ & 0.36 \\
WBC $\left(10^{3} / \mathrm{mm}^{3}\right)$ & $10.30 \pm 0.54$ & $9.90 \pm 0.46$ & 0.57 \\
\hline PLT $\left(10^{3} / \mathrm{mm}^{3}\right)$ & $147.54 \pm 6.64$ & $240.2 \pm 11.44$ & $0.05^{*}$ \\
$\mathrm{Hb}(\mathrm{g} / \mathrm{dL})$ & $11.72 \pm 0.27$ & $11.50 \pm 0.29$ & 0.50 \\
\hline $\mathrm{Ht}(\%)$ & $34.51 \pm 0.81$ & $33.72 \pm 0.53$ & 0.42 \\
\hline
\end{tabular}

RBC, red blood cells; WBC, white blood cells; PLT, platelets; Hb, Hemoglobin; Ht, Hematocrit; *Statistically significant $(<0.05)$.

Table 3. Hepatic biomarkers of study groups $($ mean \pm SD).

\begin{tabular}{lccc} 
Analytes & Preeclamptic group $(n=60)$ & Control group $(n=60)$ & $0.026^{*}$ \\
AST (U/L) & $28.10 \pm 3.89$ & $15.33 \pm 0.89$ & $0.01^{*}$ \\
ALT (U/L) & $20.51 \pm 3.19$ & $10.70 \pm 0.42$ & $0.035^{*}$ \\
\hline ALP (U/L) & $193.50 \pm 7.67$ & $162.57 \pm 9.12$ & $0.01^{*}$ \\
GGT (U/L) & $26.89 \pm 5.86$ & $9.08 \pm 0.45$ & \\
\hline
\end{tabular}

ALT, alanine aminotransferase; AST, aspartate aminotransferase; ALP, alkaline phosphatase; GGT, Gamma-Glutamyl-Transferases; *Statistically significant $(<0.05)$.

Table 4. Renal function and lipid profile parameters of study groups (mean $\pm S D$ ).

\begin{tabular}{lccc} 
Analytes & Preeclamptic group $(\mathrm{n}=60)$ & Control group $(\mathrm{n}=60)$ & p-value \\
Tot cholesterol $(\mathrm{g} / \mathrm{L})$ & $2.94 \pm 0.15$ & $1.64 \pm 0.08$ & $0.001^{*}$ \\
Triglycerides $(\mathrm{g} / \mathrm{L})$ & $3.22 \pm 0.18$ & $1.93 \pm 0.10$ & $0.001^{*}$ \\
\hline Urea $(\mathrm{g} / \mathrm{L})$ & $0.30 \pm 0.03$ & $0.18 \pm 0.01$ & $0.001^{*}$ \\
Creatinine $(\mathrm{mg} / \mathrm{L})$ & $38.07 \pm 1.95$ & $9.73 \pm 0.68$ & $0.001^{*}$ \\
\hline Uric acid $(\mathrm{mg} / \mathrm{L})$ & $72.60 \pm 3.34$ & $38.06 \pm 1.96$ & $0.001^{*}$ \\
Sodium $(\mathrm{mmol} / \mathrm{L})$ & $135.13 \pm 0.50$ & $138.40 \pm 0.34$ & $0.038^{*}$ \\
\hline Potassium $(\mathrm{mmol} / \mathrm{L})$ & $4.27 \pm 0.08$ & $3.98 \pm 0.07$ & $0.009^{*}$ \\
Albumin $(\mathrm{g} / \mathrm{L})$ & $33.35 \pm 0.67$ & $37.03 \pm 0.44$ & $0.0006^{*}$ \\
\hline Tot. Prot $(\mathrm{g} / \mathrm{L})$ & $66.51 \pm 1.36$ & $70.13 \pm 1.23$ & $0.048^{*}$ \\
\hline
\end{tabular}

*Statistically significant $(<0.05)$.

Table 5. Degree of association between parameters studied among preeclamptic group.

\begin{tabular}{|c|c|c|}
\hline Variable & Correlation coefficient " $r$ " & p-value \\
\hline ALT vs Uric Acid & 0.42 & $0.03 *$ \\
\hline ALT us Urea & 0.76 & 0.06 \\
\hline ALT us Creatinine & 0.52 & $0.046^{*}$ \\
\hline AST us Uric Acid & 0.73 & 0.05 \\
\hline AST us Urea & 0.24 & $0.036^{*}$ \\
\hline AST us Creatinine & 0.52 & 0.11 \\
\hline Potassium vs Urea & 0.60 & $0.004 *$ \\
\hline Potassium vs Creatinine & 0.66 & $0.001^{*}$ \\
\hline Potassium vs Uric acid & 0.52 & $0.003^{*}$ \\
\hline Sodium vs Urea & 0.15 & 0.41 \\
\hline Sodium vs Creatinine & 0.41 & 0.10 \\
\hline Sodium vs Uric acid & 0.09 & 0.61 \\
\hline Urea vs Creatinine & 0.74 & $0.026^{*}$ \\
\hline Urea vs Albumin & 0.20 & $0.023^{*}$ \\
\hline Urea us Uric Acid & 0.74 & $0.0271^{*}$ \\
\hline Uric Acid vs Creatinine & 0.65 & $0.041^{*}$ \\
\hline Uric Acid vs Albumin & 0.29 & 0.12 \\
\hline
\end{tabular}

*Statistically significant $(<0.05)$. 


\section{Discussion}

Previous studies reported a significant difference between the maternal ages in case of PE compared to normotensive pregnant women. The risk of PE has increased exponentially with maternal age, especially after the age of 40, and it was two times higher compared to women under 35 years old, ${ }^{20}$ since there is a higher incidence of chronic hypertension in older women. ${ }^{21}$

Overweight and obesity have been described as a potential risk factor by many earlier studies. ${ }^{3,22}$ Hypertension, another important sign in preeclampsia, is often present in obese subjects and its prevalence significantly increases with obesity, this can be the result of insulin resistance associated with the predominance of vasoconstrictors over vasodilators. ${ }^{4}$

In the present study, the fact that age, or obesity were not determining factors of PE could be due to the probable selection bias or to the small control population.

Similar to ours finding, Makuyana et al., ${ }^{23}$ didn't observe a significant difference in haematological parameters as well as the rate of $\mathrm{Hb}$ when $\mathrm{PE}$ and severely $\mathrm{PE}$ patients were compared with controls. In addition, in their study Girling et al., ${ }^{24}$ indicated a significant decrease in the number of PLT' PE patients compared with healthy pregnant women. Platelets have a very important role in clotting, so an excessive decline in their rate leads a hemorrhagic risk, but an increased rate leads to a risk of thrombosis by formation of aggregates. ${ }^{25}$

Previous studies had found significantly raised levels of AST, ALT, ALP, and GGT in PE women. ${ }^{7,24,25}$ However, Makuyana et al., ${ }^{23}$ in Zimbabwe, did not find a significant difference between ALT levels in PE women. Furthermore, Hussein ${ }^{26}$ has indicated non-significant difference in AST between Irakian preeclamptic patients and normotensive pregnant women.

It is thought that PE and eclampsia causes hepatocellular dysfunction reflected by the elevation of serum transaminases and/or alkaline phosphatase. This possibly translate into a full clinical presentation of PE during late pregnancy, and are due to hypoxic effect of this disorder on their livers, since hypoxia results in necrosis with a degeneration of hepatocytes. ${ }^{7}$ The primary fluctuations in liver's function evaluation may be due to red cell demolition, alteration of membrane permeability and damage of hepatocytes. ${ }^{24}$ The GGT levels can be three times higher than the upper reference value in more than $50 \%$ of patients with a disease of nonalcoholic liver, but there is scientific evidence that, it is associated with increased risk of major vascular and non-vascular outcomes, hypertension and diabetes. ${ }^{27}$

Various studies have mentioned elevated levels of renal markers, such as serum uric acid, creatinine, and urea among preeclamptic volunteers compared to normotensive pregnant women. ${ }^{10,12,28}$ Thus, elevated levels of serum uric acid and creatinine in pregnant women with hypertension are due to decreased urinary clearance secondary to reduced Glomerular Filtration Rate (GFR) and increased reabsorption. ${ }^{29}$

Serum uric acid is not only a marker of severity of PE, but has also been interpreted to act as an important cofactor involved in the pathogenesis of this disorder. ${ }^{28}$ The increase in serum uric acid is an early change in pregnancies complicated by PE occurring as early as 24-25 weeks' gestation, and even occurs earlier in women who develop preeclampsia later. ${ }^{30}$

The decrease in GFR and Renal Plasma Flow (RPF) can eventually decrease sodium delivery to the distal nephron and potassium secretion in case of PE; this suggests the possibility of inhibition of urinary potassium excretion before. This observation sug- gests that PE could be associated with hyponatremia and rise of potassium levels. ${ }^{25}$

The decrease in total protein as well as albumin levels in PE patients confirms the generally known concept of hypoalbuminemia as a feature of complicated pregnancies by $\mathrm{PE},{ }^{31}$ which is related to endothelial damage leading to enhanced capillary permeability. ${ }^{23}$

In the current study, lipid levels in women with preeclampsia were higher than those in healthy pregnant women, which corroborate with findings of a meta-analysis showing that maternal serum total cholesterol and triglyceride levels during pregnancy are elevated during the first/second and third trimesters in PE women compared with normotensive pregnant women. ${ }^{32}$

Many studies observed that PE preceded by dyslipidaemia, higher ratio of free fatty acids a to albumin, increased lipolytic activity, and enhanced endothelial uptake of free fatty acids, which are esterified to triglycerides particularly, Preeclamptic women had both and, resulting in which indicates that hypertriglyceridemia and elevated lipoprotein may be etiologic and pathophysiologic mechanism responsible for PE. ${ }^{8}$ This can be explained by aggravated damage of the liver inhibiting the enhanced de novo synthesis of triglyceride. ${ }^{33}$

An assessment of the degree of association among the parameters studied in preeclampsia shows a positive association between liver transaminases and biomarkers of renal function (uric acid, urea, and creatinine), suggesting the possible association of higher risk of hepatic and renal injuries with PE. ${ }^{25}$

This study indicates that PE is a pregnancy disorder causing major liver and renal dysfunctions and resulting in a significant electrolyte imbalance. Evaluating hepatic (especially ALT) and renal biomarkers, as well as the platelet count and lipid profile in case of PE, may help to warrant close maternal and fetal follow-up, in addition to targeted monitoring strategies of women who already have preeclampsia for comprehension of the nature and risks of this disease. Further studies on maternal and neonatal outcomes in cases of PE are needed for a better understanding of this disease's pathophysiology in Algeria.

\section{References}

1. WHO. The World Health Report 2005 - make every mother and child count. World Health Organization; 2005. Available from: https://www.who.int/whr/2005/en/

2. Tranquilli AL, Dekker G, Magee L, et al. The classification, diagnosis and management of the hypertensive disorders of pregnancy: a revised statement from the ISSHP. Pregnancy Hypertens 2014;4:97-104.

3. Chen Y, Lin S, Chen H, et al. Hyperkalemia associated with prolonged magnesium sulfate administration in preeclampsia. Acta Nephrologica 2010;24:8-15.

4. Anderson NH, Mc Cowan LM, Fyfe EM, et al. The impact of maternal body mass index on the phenotype of pre-eclampsia: a prospective cohort study. Int J Obst Gynaecol 2012;119:589-95.

5. Endeshaw M, Ambaw F, Aragaw A, Ayalew A. Effect of maternal nutrition and dietary habits on preeclampsia: A case-control study. Int J Clin Med 2014;5:1405-16.

6. Ye C, Ruan Y, Zou L, et al. The 2011 survey on hypertensive disorders of pregnancy (HDP) in China: prevalence, risk factors, complications, pregnancy and perinatal outcomes. PloS One 2014;9:e100180.

7. Das S, Char D, Sarkar S, et al. Evaluation of liver function test 
in normal pregnancy and pre-eclampsia: a case control. J Dent Med Sci 2013;12:30-2.

8. Kozic JR, Benton SJ, Hutcheon JA, et al. Abnormal liver function tests as predictors of adverse maternal outcomes in women with preeclampsia. J Obstet Gynaecol Can 2011;33:995-1004.

9. Hussein W, Lafayette RA. Renal function in normal and disordered pregnancy. Curr Opin Nephrol Hypertens 2014;23:46-53.

10. Padma Y, Aparna VB, Kalpana B, et al. Renal markers in normal and hypertensive disorders of pregnanacy in Indian women: a pilot study. Int J Reprod Contracept Obs Gynecol 2013;2:514-20.

11. Lorentzen B, Henrisksen T. Plasma lipids and vascular dysfunction in preeclampsia. Semin Reprod Endocrinol 1998;16:33-9.

12. Brown MA, Lindheimer MD, de Swiet M, et al. The classification and diagnosis of the hypertensive disorders of pregnancy: statement from the International Society for the Study of Hypertension in Pregnancy (ISSHP). Hypertens Pregnancy 2001;20:IX-XIV.

13. Reitman S, Frankel S. A colorimetric method for determination of serum glutamic -osaloacetic and glutamic - pyruvic transaminases.Am J Clin Pathol 1957;28:56-61.

14. IFCC method for the measurement of ALP. J Clin Chem Clin Biochem 1983;21:731-48.

15. Szasz G. New substrates for measuring gamma-glutamyl transpeptidase activity. Z Clin Chem KIin Biochem 1974; $12: 228$.

16. Fogh-Andersen N, Wimberley PD, Thode J, SiggaardAndersen O. Determination of sodium and potassium with ionselective electrodes. Clin Chem 1984;30:433-6.

17. Grove TH. Effect of reagent $\mathrm{pH}$ on determination of high-density lipoprotein cholesterol by precipitation with sodium phosphotungstate -magnesium. Clin Chem 1979;25:560-4.

18. Bulgar HA, Johns HE. The determination of plasma uric acid. J Biol Chem 1941;140:427.

19. Luxton RW, Patel P, Keir G, et al. A micro-method for measuring total protein in cerebrospinal fluid by using benzethonium chloride in microtiter plate wells. Clin Chem 1989;35:1731-4.

20. Abubakar A, Abdullah RA, Jibril HZ, et al. Maternal Ethnicity and Severity of Pre-Eclampsia in Northern Nigeria. Asian J Med Sci 2009;1:104-7.

21. Shoelson SE, Herrero L, Naaz A. Obesity, inflammation, and insulin resistance. Gastroenterol 2007;132:2169-80.

22. Anuradha R, Durga T. Estimation of lipid profile among preeclampsia woman by comparing with normal pregnancy. Int J Contemp Med Res 2016;3:1958-61.

23. Makuyana D, Mahomed K, Shukusho FD, Majoko F. Liver and kidney function tests in normal and pre-eclamptic gestation - a comparison with non-gestational reference values. Cent Afr J Med 2002;48:55-9.

24. Girling JC, Dow E, Smith JH. Liver function test in preeclampsia: importance of comparison with reference range derived from normal pregnancy. British J Obstet Gynaecol 1997;104:246-50.

25. Ekun OA, Olawumi OM, Makwe CC, Ogidi NO. Biochemical Assessment of Renal and Liver Function among Preeclamptics in Lagos Metropolis. Hindawi Int J Reprod Med 2018:1-6.

26. Hussein ZG. Study of liver and kidney functions in non-pregnant, pregnant and preeclamptic women. J Baghdad Sci 2012;9:277-284.

27. Mauro P, Renze B, Wouter W. Enzymes. In: Tietz text book of clinical chemistry and molecular diagnostics.4th edition. Carl AB, Edward R, David EB (eds). Elsevier; 2006. pp 604-16.

28. Vyakaranam S, Bhongir A, Patlolla D, Chintapally R. Study of serum uric acid and creatinine in hypertensive disorders of pregnancy. Int J Med Sci Pub Health 2015;4:1424-8.

29. Jeyabalan A, Conrad KP. Renal function during normal pregnancy and preeclampsia. Front Biosci 2007;12:2425-37.

30. Powers RW, Bodnar LM, Ness RB, et al. Uric acid concentrations in early pregnancy among preeclamptic women with gestational hyperuricemia at delivery. Am J Obstet Gynecol 2006;194:160.e1-8.

31. Muzammil S, Khayyam KU, Siddiqui AN. Serum protein ratio in normal and pre-eclamptic women of primiparous and multiparous in relation to age. Int J Basic Appl Med Sci 2014;4:331-5.

32. Spracklen CN, Smith CJ, Saftlas AF, et al.Hyperlipidemia and Preeclampsia Meta-Analysis. Am J Epidemiol 2014;180:346-58.

33. Islam NAF, Chowdhury MAR, Kibria GM, Akhter S. Study of serum lipid profile in pre-eclampsia and eclampsia. Faridpur Med Coll J 2010;5:56-9. 